\title{
Numerical Simulation of Effects of River Reconstruction on Flooding: A Case Study of the Ba River, China
}

\author{
Haixiao Jing $\mathbb{D},{ }^{1}$ Yongbiao Lang, ${ }^{2}$ Xinhong Wang $\mathbb{D},{ }^{1}$ Mingyang Yang, ${ }^{1}$ and Zongxiao Zhang ${ }^{1}$ \\ ${ }^{1}$ State Key Laboratory of Eco-Hydraulics in Northwest Arid Region of China, Xi'an University of Technology, Xi'an 710048, China \\ ${ }^{2}$ Qinghai Research Institute of Investigation \& Design of Water Conservancy \& Hydropower, Xining 810001, China \\ Correspondence should be addressed to Xinhong Wang; wxh@mail.xaut.edu.cn
}

Received 25 January 2021; Revised 19 February 2021; Accepted 24 February 2021; Published 5 March 2021

Academic Editor: Yanhu Mu

Copyright (c) 2021 Haixiao Jing et al. This is an open access article distributed under the Creative Commons Attribution License, which permits unrestricted use, distribution, and reproduction in any medium, provided the original work is properly cited.

The local reconstruction of river channels may pose obstacles of flood flow, local eddy currents, or high flow velocity which pose potential threats to human life and infrastructures nearby. In the design of such projects, the effects of local reconstruction of the river channel on flooding are often evaluated by the one-dimensional method, which is based on the formula of one-dimensional nonuniform flow. In this study, a two-dimensional hydrodynamic model based on shallow water equations is employed to investigate the impacts of river reconstruction on flooding in the Ba River, China. The finite volume method and an unstructured triangular mesh are used to solve the governing equations numerically. The numerical model is validated by comparison with the results of a physical model of 1:120 scale. The backwater effects and impacts of flood flow fields under two flood frequencies are analyzed by comparing the numerical results before and after local reconstruction. The results show that the backwater length under both 10-year and 100-year floods can be reached up to the upstream boundary of the computational domain. However, the maximum water level rises are limited, and the levees in this river channel are safe enough. The flow velocity fields under both floods are changed obviously after local reconstruction in the Ba River. Areas with the potential for scour and deposition of the river bed are also pointed out. The findings of this study are helpful for the evaluation of flood risks of the river.

\section{Introduction}

River flooding, which is commonly caused by sudden and intense rainfalls or storms in the river's watershed, can cause loss of human lives and serious damage to infrastructures and properties along the river. Furthermore, with the climate change (such as global warming) in recent years, it has been found that extreme rainfalls occur more intensely and therefore result in more serious floods $[1,2]$. For river channels through urban areas, hydraulic structures such as weirs and artificial islands are often designed to raise the water level upstream where wetlands or parks are built to improve the scenery nearby. For the design of such hydraulic structures, flooding is treated as one of the most important factors. In addition, the presence of such structures will affect the flooding of the river channel. Therefore, proper evaluation of the impact of river reconstruction on river floods is of great help for the design of river projects and flood risk management of the river channel.

Traditionally, during the design of hydraulic structures, the effects on river flooding are mostly evaluated by the onedimensional (1D) method which is based on the law of conservation of energy $[3,4]$. In this method, the main emphasis is placed on backwater effects. Besides this, the unsteady 1D method based on shallow water equations or Saint-Venant equations is applied widely to evaluate the flood risks of river channels. Forster et al. [5] investigated the flooding and emptying process of a proposed storage area on the Middle Elbe River, where a 1D hydrodynamic model was used for a $20 \mathrm{~km}$ reach of the Elbe River and the storage area was modeled by two storage cells each representing one polder basin. Tomasz et al. [6] studied the impact of a bridge on flooding of the Warta River near Wronki in Poland using the 1D HEC-RAS package. Petaccia and Natale [7] 
developed a 1D numerical model (ORSADEM) and applied it to analyze flood inundation of the Brembo River. Generally, because of their lower computational cost, 1D numerical models have been widely used for the evaluation of river floods. However, for the complex topography of local river channels, such as the curvature and bifurcation, the flow fields are complex and vary in two horizontal coordinates, so the 1D model cannot reproduce the details of the flow fields. Consequently, coupled 1D and 2D models or 2D models were developed and employed to predict flood inundation [8-11].

With the development of the LIDAR technique $[12,13]$, message passing interface (MPI), and graphic processing unit (GPU) techniques [14-16] in recent years, digital elevation model (DEM) data can be obtained efficiently, and the computational efficiency of 2D models has been improved greatly, promoting the development and application of 2D hydrodynamic models. $1 \mathrm{D}$ and $2 \mathrm{D}$ unsteady and nonuniform flow modeling of the flood wave routed down river valleys has been presented, including modeling of a channel bifurcation at the confluence and backwater effects [8]. A coupled 1D and 2D hydrodynamic model for flood risk management in urban areas was developed to overcome the drawbacks of each individual modeling approach, and an additional module was used to simulate the rainfall-runoff process in study areas [9]. Using MIKE 21 FM, Wang et al. [10] investigated the effects of bridge piers on river floods in the Jialing River, China. Ahn et al. [17] carried out a numerical simulation to predict the urban inundation area due to extreme rainfall using the Mike21 model. Full-scale fluvial flood modeling over large catchments was carried out using coupled hydrological and hydraulic/hydrodynamic models [11]. By using a multiple modern GPU acceleration technique, more than 2.5 times faster than real time was achieved although it involved 100 million computational cells inside the computational domain. In general, the $2 \mathrm{D}$ numerical models are expected to predict the flood flow fields more accurately, which is of great help for the design of hydraulic projects and the management of flood risks.

In this study, the effects of local river reconstruction in the Ba River on flooding are studied by employing a $2 \mathrm{D}$ hydrodynamic model. The backwater effects due to the reconstruction of the river channel are analyzed. The velocity fields before and after local reconstruction are also compared and analyzed. The remainder of this study is structured as follows. The study areas and details of the numerical model and validation are presented in Section 2 , where the results of a physical model of $1: 120$ scale are used to validate the accuracy of the numerical model developed. In Section 3, backwater effects and flow fields before and after local reconstruction are investigated for two different flood frequencies. According to the flow field results, local scour or deposition of the river channel after reconstruction is also analyzed. Finally, the main conclusions are drawn in Section 4.

\section{Materials and Methods}

2.1. Study Area. The Ba River, which is one of the main tributaries of the Wei River, originates from the north of the Qinling Mountains, with a total length of $104 \mathrm{~km}$ and a total watershed area of $2581 \mathrm{~km}^{2}$. The upper reach of the $\mathrm{Ba}$ River is in the Qinling Mountains, where the terrain is high in the south and low in the north. The average bed slope in the upper reach is about $9 \%$, and floods rise and fall rapidly with a small amount of sediment. The middle and lower reaches of the Ba River have bed slopes of $2.35 \%$ and $1.58 \%$, respectively. According to statistics from the Maduwang hydrological station, the maximum flood peak discharge of the Ba River is $2160 \mathrm{~m}^{3} / \mathrm{s}$ (August 12, 1953), the multiyear average discharge is $16.8 \mathrm{~m}^{3} / \mathrm{s}$, and the annual total runoff is 529 million $\mathrm{m}^{3}$. The runoff from July to August is $42.7 \%$ that of the whole year, while from December to February of the following year, the runoff is only $6.7 \%$ that of the whole year. The annual average sediment concentration is $5.4 \mathrm{~kg} / \mathrm{m}^{3}$, and the annual average sediment load is 2.86 million tons.

The project area is located in the lower reach of the $\mathrm{Ba}$ River, which flows through Xi'an city, then into the Wei River, and finally into the Yellow River, as can be seen in Figure 1. The lower reach of the Ba River has a total length of $8.17 \mathrm{~km}$. Three weirs have been built in this reach; these are the 0\# weir, 1\# weir, and Guangyuntan weir from downstream to upstream. The levees in this reach are designed for 100-year floods with a peak discharge of $3300 \mathrm{~m}^{3} / \mathrm{s}$. With the purpose of building an artificial lake for the 2021 National Games of China, in this project, the reach between Guangyuntan weir and 1\# weir, which is about $2.5 \mathrm{~km}$ long, is reconstructed by widening the cross section locally and building two artificial islands. With this reconstruction, the water level upstream of the 1 \# weir will be increased to meet the landscape requirement in this area. However, after local reconstruction, the flood risks in this reach will be changed and must be evaluated carefully. Scientific suggestions or guides must be provided for a better design of this project, which is the purpose of this study.

2.2. Model Description. In this study, a well-documented software MIKE 21 FM, which was developed by the Danish Hydraulic Institute (DHI), was used. The governing equations (in the Cartesian coordinate system) of the model are the two-dimensional shallow water equations, given by 


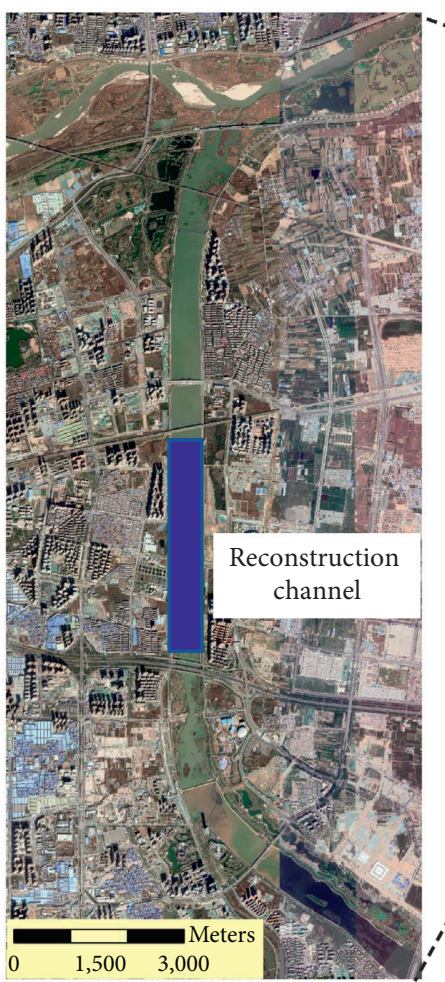

(a)

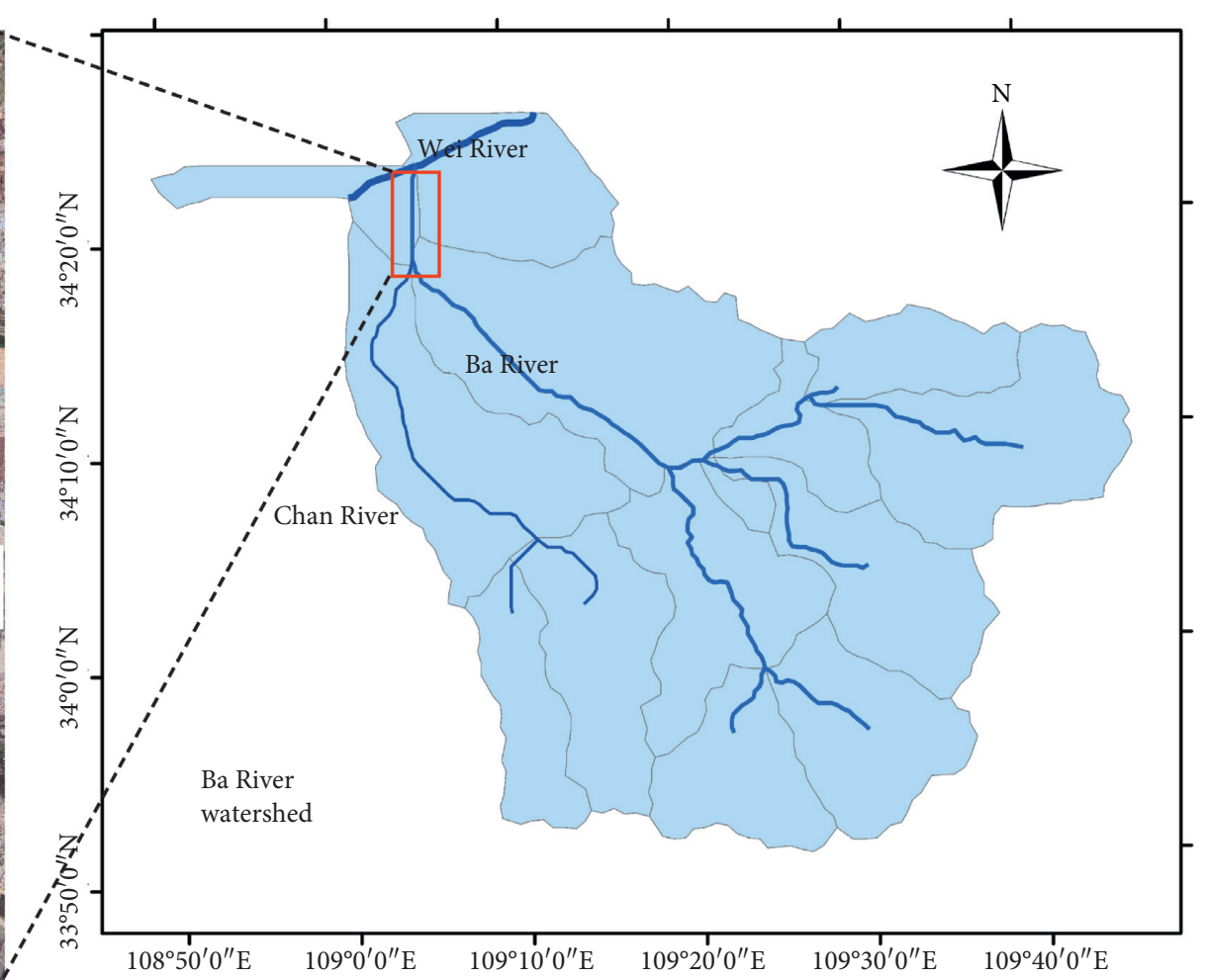

(b)

FIGURE 1: Location of the project area: (a) project river channel; (b) watershed of the Ba River.

$$
\begin{array}{r}
\frac{\partial h}{\partial t}+\frac{\partial h \bar{u}}{\partial x}+\frac{\partial h \bar{v}}{\partial x}=0, \\
\frac{\partial h \bar{u}}{\partial t}+\frac{\partial h \bar{u}^{2}}{\partial x}+\frac{\partial h \bar{u} \bar{v}}{\partial y}+g h \frac{\partial \zeta}{\partial x}+\frac{g \bar{u} \sqrt{\bar{u}^{2}+\bar{v}^{2}}}{C^{2}}-\frac{1}{\rho}\left[\frac{\partial}{\partial x}\left(h \tau_{x x}\right)+\frac{\partial}{\partial y}\left(h \tau_{x y}\right)\right]=0, \\
\frac{\partial h \bar{v}}{\partial t}+\frac{\partial h \overline{u v}}{\partial x}+\frac{\partial h \bar{v}^{2}}{\partial y}+g h \frac{\partial \zeta}{\partial y}+\frac{g \bar{v} \sqrt{\bar{u}^{2}+\bar{v}^{2}}}{C^{2}}-\frac{1}{\rho}\left[\frac{\partial}{\partial x}\left(h \tau_{x y}\right)+\frac{\partial}{\partial y}\left(h \tau_{y y}\right)\right]=0,
\end{array}
$$

where $t$ is the time; $x$ and $y$ are the horizontal coordinates; $h$ is the total water depth; $\zeta$ is the free surface elevation; and $\bar{u}$ and $\bar{v}$ are the depth-averaged velocities in the $x$ and $y$ directions, respectively. $g$ denotes gravitational acceleration; $C$ is the Chezy resistance, which is calculated by the Manning formula. $\rho$ is the water density; and $\tau_{x x}, \tau_{x y}$, and $\tau_{y y}$ are components of effective shear stress.

The finite volume method was employed to solve the above equations numerically, and a triangular mesh was used. Specifically, the second-order Runge-Kutta method was applied for the time integration. An approximate Riemann solver (Roe's scheme) was used to calculate the fluxes at cell boundaries. A linear gradient reconstruction technique was employed to achieve second-order spatial accuracy. To avoid numerical oscillations, a second-order TVD slope limiter (Van Leer limiter) was used. More details about the numerical method can be found in the MIKE $21 \mathrm{FM}$ manual [18].
To ensure stability during simulation, the time step was adjusted according to the CFL (Courant-Friedrichs-Lewy) number, which is defined as

$$
\mathrm{CFL}_{H D}=(\sqrt{g h}+|u|) \frac{\Delta t}{\Delta x}+(\sqrt{g h}+|v|) \frac{\Delta t}{\Delta y},
$$

where $\Delta x$ and $\Delta y$ are the mesh sizes in the $x$ and $y$ directions, which are approximately the minimum side length of the triangular meshes, and $\Delta t$ is the time step.

2.3. Numerical Model Setup. The topographies before and after reconstruction of the river channel are presented in Figure 2; these were provided by the Xi'an Water Conservancy Planning Survey and Design Institute, China. For irregular land boundaries, a high-quality unstructured mesh is of great importance to ensuring an accurate numerical simulation. The computational meshes in this study were 


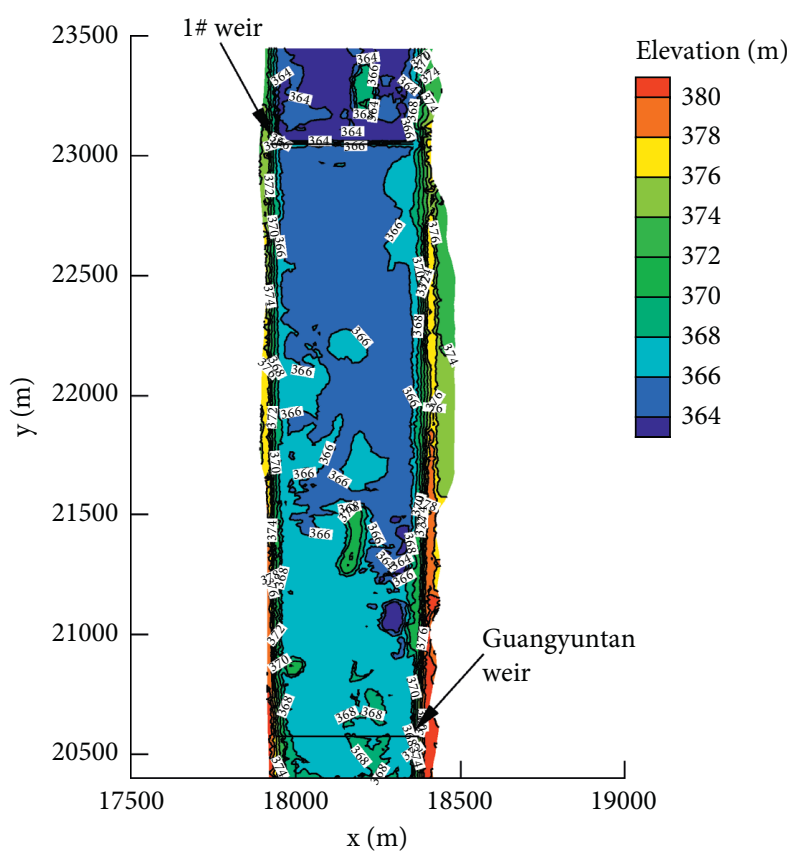

(a)

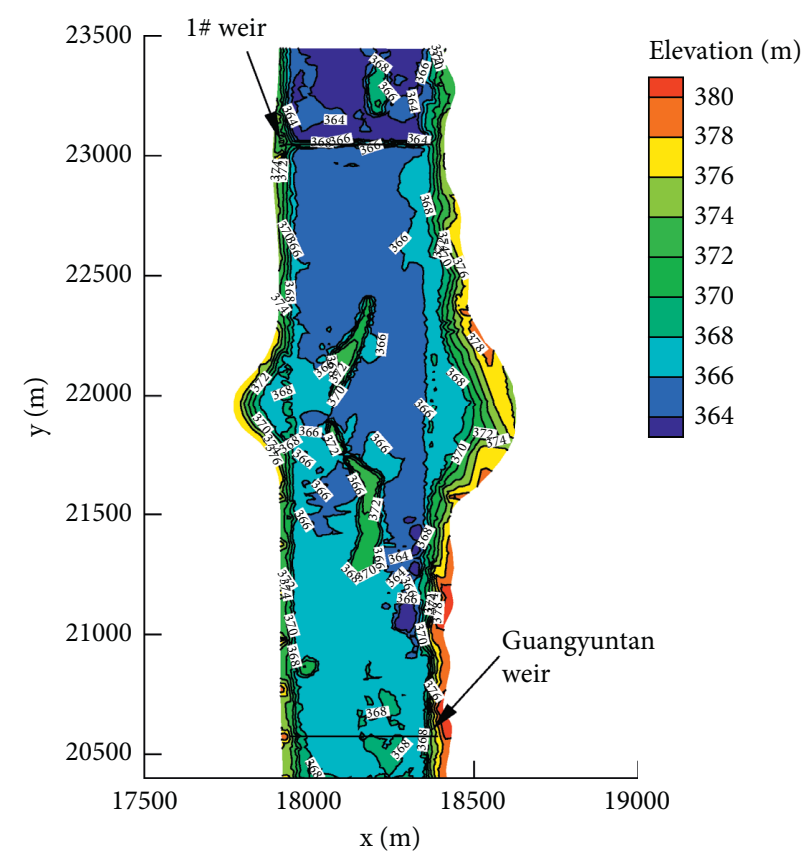

(b)

Figure 2: Topographies of the river channel. (a) Before reconstruction. (b) After reconstruction.

generated using the Mesh Generator provided by MIKE software. To ensure the quality of the generated mesh, three parameters, the maximum element area, the smallest allowable angle, and the maximum number of nodes, were provided by Mesh Generator. In this study, we chose the maximum element area as $150 \mathrm{~m}^{2}$, the smallest allowable angle as 29 degrees, and the maximum number of nodes as 100,000 . For the computational domain before reconstruction, there were a total of 17132 elements, while a total of 18411 elements were generated in the mesh of the computational domain after reconstruction. The two sets of meshes before and after local reconstruction were used to investigate the impacts of local reconstruction of the river channel on flooding. Note that the artificial islands, which may be submerged during floods, were identified automatically by the wet and dry boundary method during the simulation.

The Manning coefficient $n$, which represents the overall resistance of the channel bed, is one of the key parameters for flood simulation. In this study, a constant Manning coefficient $\left(n=0.03 \mathrm{~m}^{-1 / 3} \mathrm{~s}\right)$ was used, which was calibrated by results of a physical model, as detailed in the following section.

Boundary conditions at the upstream and downstream cross sections are also important and have to be specified carefully. In this study, steady-state conditions were taken into account to provide guides for engineering design. Hence, maximum flood discharges were used at the upstream boundary, and constant water levels were used at the downstream boundary. Two scenarios with 10-year and 100year floods are analyzed in this study. From hydrological analysis, the peak discharges of 10-year and 100-year floods in this river are $1700 \mathrm{~m}^{3} / \mathrm{s}$ and $3300 \mathrm{~m}^{3} / \mathrm{s}$, respectively. Water levels at the downstream boundary are affected by several factors such as the topography of the downstream channel and the water level of the Wei River downstream. After careful analysis, the corresponding water levels at downstream boundary are determined to be $369.48 \mathrm{~m}$ and $370.55 \mathrm{~m}$ for the 10-year and 100-year floods, respectively. Due to the steady-state condition, the initial water levels can be set arbitrarily, and in this study, constant water level the same as the water level at the downstream boundary was used and the initial velocities were set to zeros.

Time step was self-adaptive according to the CFL condition. During computation, the depth at each element was monitored, and the elements were classified as dry, partially dry, or wet. Then, wet and dry interfaces were monitored to identify flooded boundaries.

2.4. Model Validation. Validation of the numerical model was undertaken by comparing it with the results of a $1: 120$ scale physical model of the reconstructed river channel. The physical model was constructed in a laboratory field of Xi'an University of Technology, China. The domain of the physical model was the same as that of the numerical model, ranging from Guangyuntan weir upstream to 1 \# weir downstream with a length of about $2.6 \mathrm{~km}$, as shown in Figure 3 . The physical model was designed according to the gravity similarity criterion. The flood water levels and velocity magnitudes at the locations of 13 cross sections with equal spatial intervals were measured, as shown in Figure 3.

The longitudinal profiles of the sectional average water levels for 10-year and 100-year floods are presented in Figure 4. For 10-year floods, it can be seen that the numerical water level agrees better with experimental data in the 

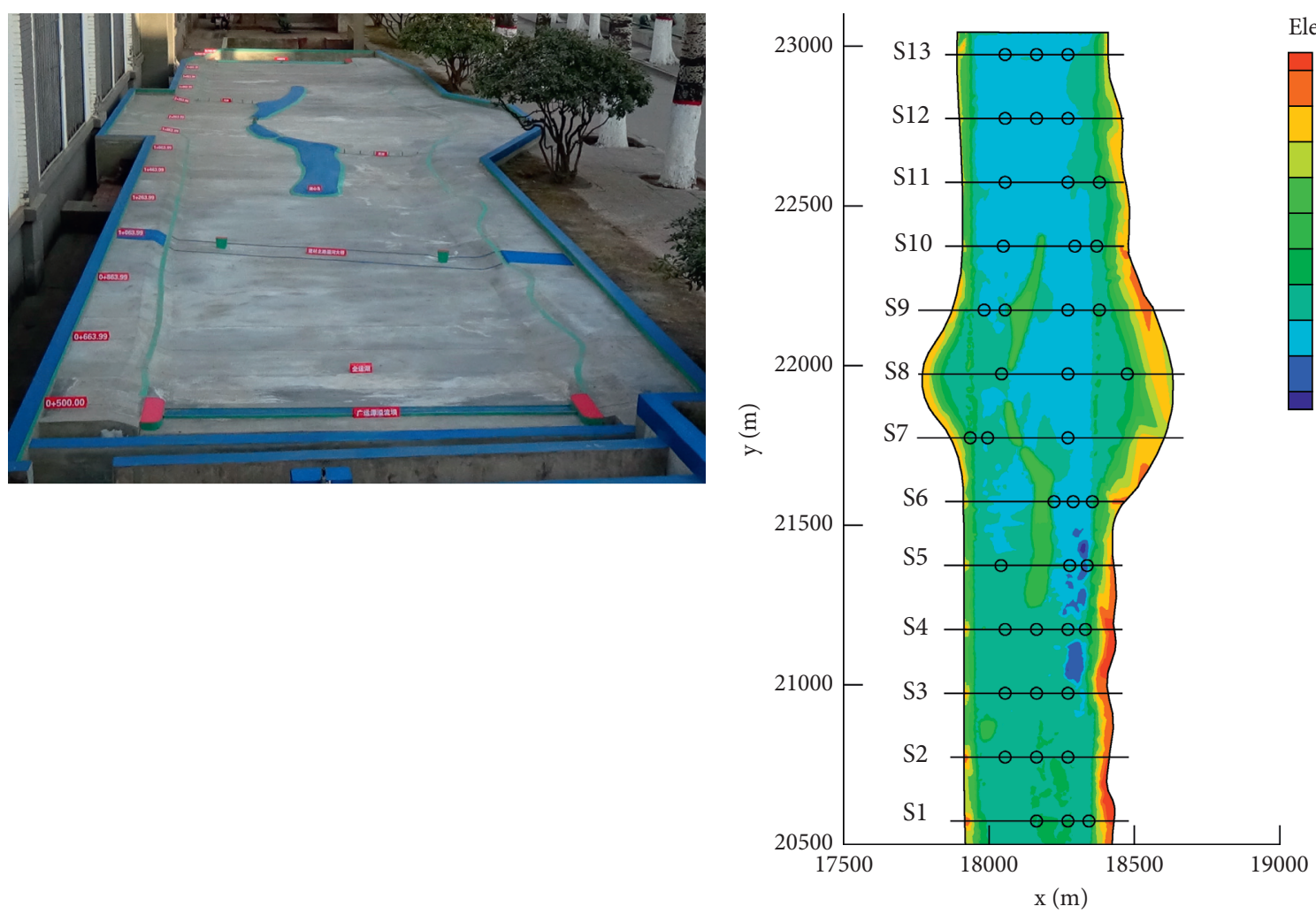

Elevation (m)

(a)

(b)

Figure 3: Physical model and measurement sections and points (circles: measurement points). (a) Picture of the physical model. (b) Measurement sections and points.

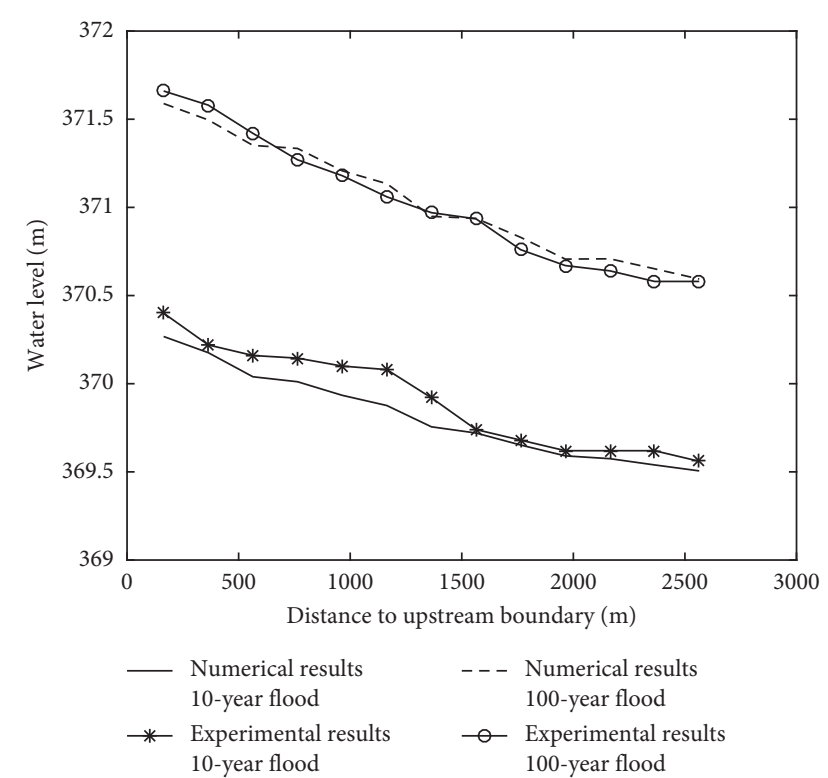

FIgURE 4: Comparison of longitudinal water level profiles.

downstream channel (distance to upstream boundary $1500 \mathrm{~m}$ to $2600 \mathrm{~m}$ ) than in the upper channel (distance to upstream boundary $0 \mathrm{~m}$ to $1500 \mathrm{~m}$ ), where backwater effects are expected due to the reconstruction of the river channel. The maximum error of the water level was $0.2 \mathrm{~m}$. For 100 - year floods, the numerical water level profile fits better with the experimental data for the entire channel, with a maximum error of $0.08 \mathrm{~m}$. In general, the numerical model can well predict the flood water level.

For the flood velocity field, it is noted that the depthaveraged velocities were obtained by the numerical model, while in the physical model, they were approximated by averaging the velocities at two vertical levels of each measurement point. Specifically, due to the small scale used in this study, the maximum water depth in the physical model was about $0.06 \mathrm{~m}$, which corresponds to $7.2 \mathrm{~m}$ in the full-scale model. Therefore, at each specific location, two velocities, one at the free surface and another near the bottom, were measured and used to approximate the depth-averaged velocity. The numerical and experimental results of velocity magnitudes at 42 points for a 100 -year flood are presented in Figure 5. The dashed line $y=0.9678 x+0.03086$ denotes a linear fit of the data, which is very close to $y=x$, representing a perfect fit of two datasets. The coefficient of determination $R^{2}$, which represents the degree of linear-correlation of variables and ranges between 0 and 1, was found to be 0.8349 (the higher the value, the better the fit). Further, the relative errors were calculated and the results show that there were 26 points with relative errors less than $10 \%$. The maximum error was $18.7 \%$ at the left point of section S8; this is probably due to the complex topography near this area. For the 10-year 


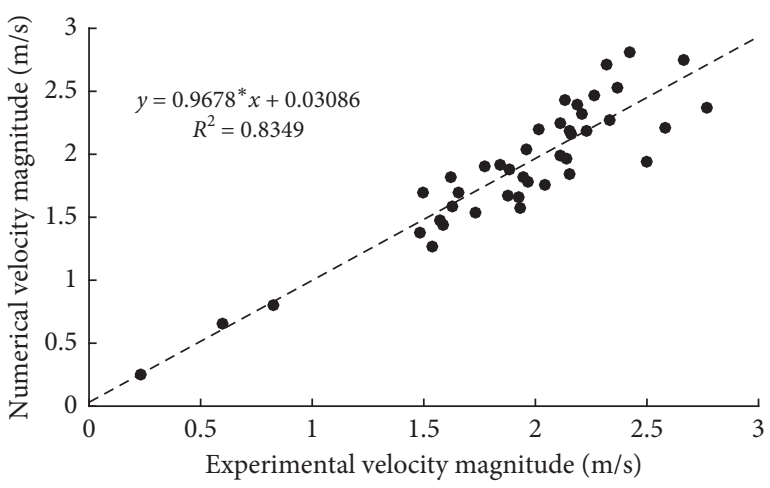

Figure 5: Comparison of flood velocity magnitudes under 100-year floods.

flood, the velocity in the physical model was too small to be measured accurately by pitot tube and will not be used here. Overall, the numerical model developed here was demonstrated to be accurate and appropriate for use in the following analysis.

\section{Results and Discussion}

The developed numerical model was applied to simulate the flood field before and after river reconstruction for two typical flood frequencies, 10-year and 100-year floods. An analysis of the effects of river reconstruction on the flood flow field was carried out by comparing the results before and after river reconstruction. The effects on both flood water elevations and flow velocity fields are analyzed, and some suggestions are then proposed to guide the project design.

3.1. Backwater Effects. Backwater effects caused by an obstruction in rivers are a common phenomenon which increase flood risk by raising the water level upstream. Comparisons of water surface profiles along the river channel before and after river reconstruction (i.e., at the 13 cross sections) are presented in Figure 6. From the figure, it can be observed that water surface elevations in the upper channel (S1 to S8) rose obviously after local reconstruction, while in the downstream channel (S9 to S13), the flood water surface elevations remained almost unchanged before and after reconstruction under both flood frequencies. The backwater effects were obvious and were mainly due to the construction of the artificial islands (S5 to S10) which blocked flood flow by reducing the river cross sections locally. For the backwater length, it was found that under both flood frequencies the effects of river reconstruction reached up to the upstream boundary (Guangyuntan weir) of the computational domain.

Quantitatively, the maximum water level rises were $0.23 \mathrm{~m}$ at section S5 for a 100 -year flood and $0.17 \mathrm{~m}$ at section S5 for a 10-year flood. The flood water surface slopes were also calculated as $0.036 \%$ and $0.041 \%$ before and after reconstruction, respectively, for a 100-year flood and $0.03 \%$ and $0.032 \%$ before and after reconstruction, respectively, for a 10-year flood.
In addition, the levees on both sides of the river were built for 100-year floods. We compared the elevations of the tops of the levees with the computed flood water surface elevations at the 13 sections. The results show that the minimum difference is $5.82 \mathrm{~m}$ at section $\mathrm{S} 13$ and the maximum difference is $10.11 \mathrm{~m}$ at section S1. This demonstrates that the levees for this river channel are safe enough. In general, the effects of local reconstruction on flood water elevation were found to be limited.

It is noted that, for the design of such a project, backwater effects are often evaluated via one-dimensional analysis, in which only cross sections are used. For complex channel sections, the local friction factor has to be determined empirically in the one-dimensional analysis. Besides this, only the cross-sectional average velocities are provided, while it is obvious that the flow field near an artificial island is two dimensional, as reported in the following subsection. Therefore, a two-dimensional method is more appropriate for this type of project.

3.2. Effects on Flow Velocity Fields. The analysis of changes in the velocity field due to local reconstruction of the river channel is also important in engineering. Local high flood velocity can cause erosion of the river bed and threaten the safety of structures, while at locations with lower flood velocity, the deposition of sediments will occur, which can have an adverse impact on structures locally.

Figures 7 and 8 present comparisons of the velocity of flood flow before and after river reconstruction for 10-year and 100-year floods. It can be observed that the flow field through the reconstructed part (S5 to S10) shows obvious changes for both flood frequency conditions. After river reconstruction, the flow between sections S5 and S10 is divided into two parts due to the presence of the artificial islands. For the 10-year flood, the maximum velocity magnitudes between S5 and S10 are about $1.0 \sim 1.5 \mathrm{~m} / \mathrm{s}$ and $1.5 \sim 2.0 \mathrm{~m} / \mathrm{s}$ before and after local reconstruction, respectively. It can also be seen that the maximum velocity is located at the right-hand part of the cross section near S5 and the left-hand part of the cross-section upstream of S10, where the areas of the cross sections are smaller. Lower velocity was found between the two artificial islands and downstream of section S10, which implies that sediment deposition near these areas must be taken into account and special attention must be paid. For the 100-year flood, the maximum velocity magnitudes between S5 and S10 are about $1.5 \sim 2.0 \mathrm{~m} / \mathrm{s}$ and $2.5 \sim 3.0 \mathrm{~m} / \mathrm{s}$ before and after local reconstruction, respectively. The location of maximum velocity is the same as that for the 10-year flood. Also, lower velocity can be seen between the two artificial islands and downstream of section S10, the same as for the 10-year flood.

Figures 9 and 10 present comparisons of the streamlines of flood flow for the 10-year and 100-year floods. It can be seen more clearly that the flood flows are almost uniform before reconstruction under both flood conditions, while after local reconstruction, the streamlines between sections S5 and S10 are obviously changed, which means that the velocity field becomes complex. In addition, the transverse 


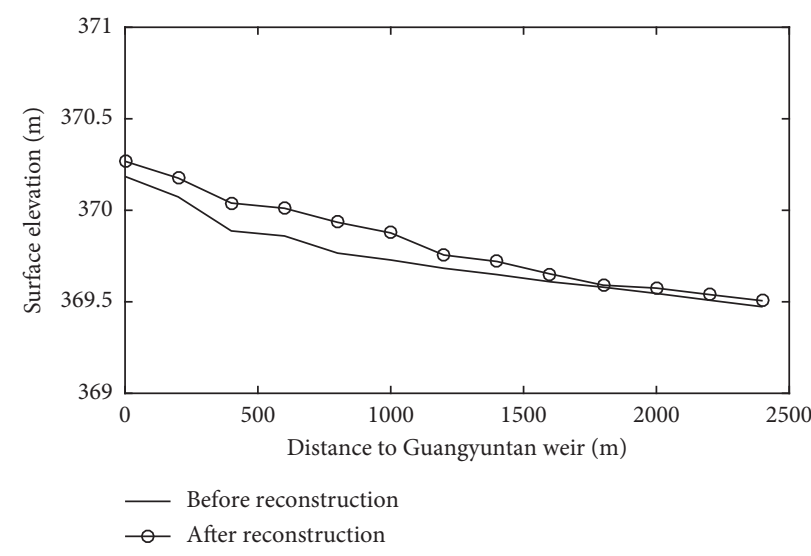

(a)

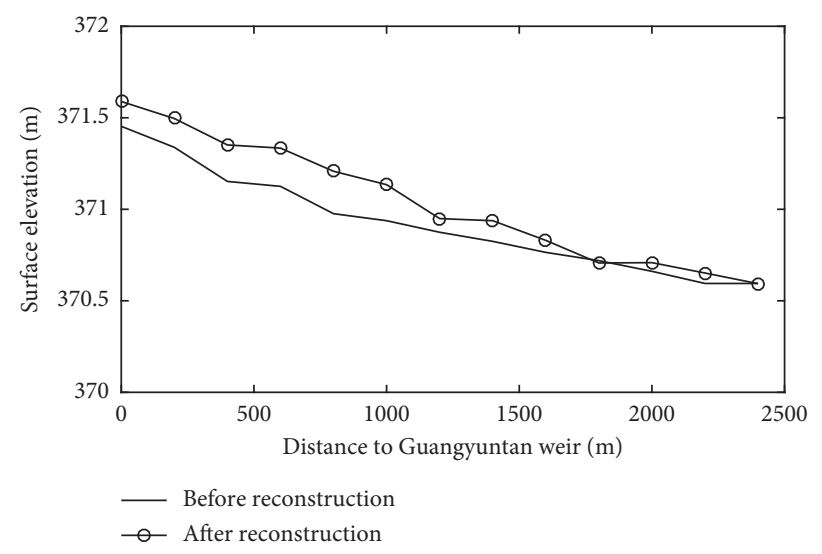

(b)

FiguRE 6: Comparisons of flood water surfaces along the river channel before and after river reconstruction. (a) 10-year flood. (b) 100-year flood.

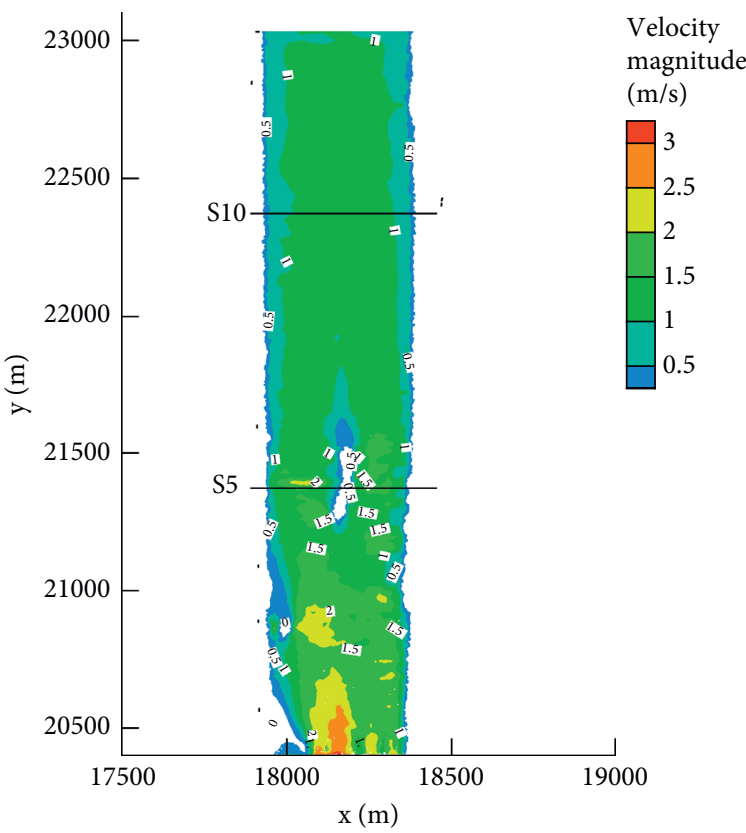

(a)

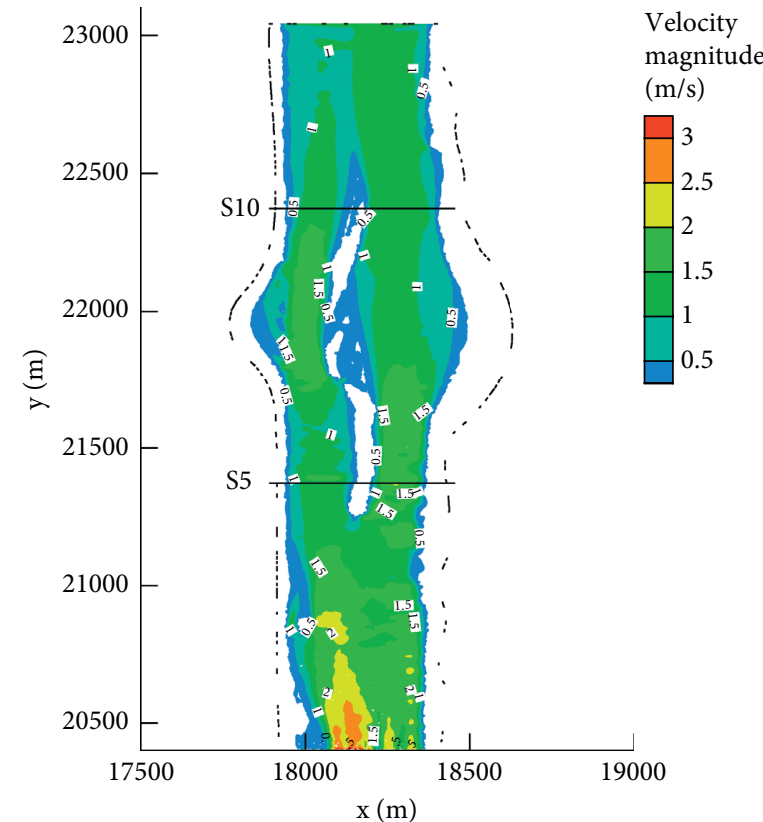

(b)

FIGURE 7: Comparisons of the velocity of flood flow before and after river reconstruction for a 10-year flood. (a) Before reconstruction. (b) After reconstruction.

velocity between S5 and S10 was found, and from quantitative analysis, the maximum transverse velocity is approximately $0.5 \mathrm{~m} / \mathrm{s}$.

From the flood velocity field above, scour and deposition of the river channel could be qualitatively analyzed. In the design of river engineering, the allowable velocities of the river channel are used empirically to determine the possibility of scour and deposition on the river bed. For coarse sand (diameter greater than $2 \mathrm{~mm}$ ), the allowable velocity is about $0.5 \sim 2.74 \mathrm{~m} / \mathrm{s}$, which means that deposition of sand will occur when the velocity is less than $0.5 \mathrm{~m} / \mathrm{s}$, while scour will occur with a velocity greater than $2.74 \mathrm{~m} / \mathrm{s}$. For fine sediment (diameter smaller than $2 \mathrm{~mm}$ ), the allowable velocity is about $0.5 \sim 1.96 \mathrm{~m} / \mathrm{s}$. From the flow velocity magnitude (Figures 7 and 8), sediment deposition will probably occur between the two artificial islands and downstream of section S10 for both 10 -year and 100-year floods. The maximum velocity between S5 and S10 for a 10-year flood is about $1.5 \sim 2.0 \mathrm{~m} / \mathrm{s}$, so the scour of sediment in this condition is limited. However, for the 100-year flood, the maximum velocity between S5 and S10 is $2.5 \sim 3.0 \mathrm{~m} / \mathrm{s}$, which implies sediment scour in this channel, so special measures must be considered. 


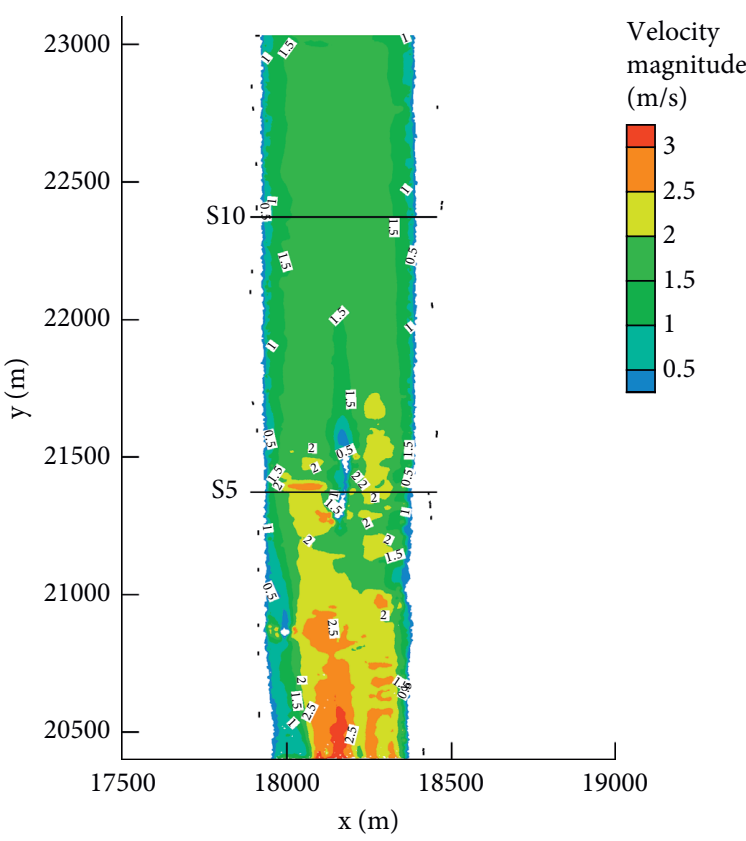

(a)

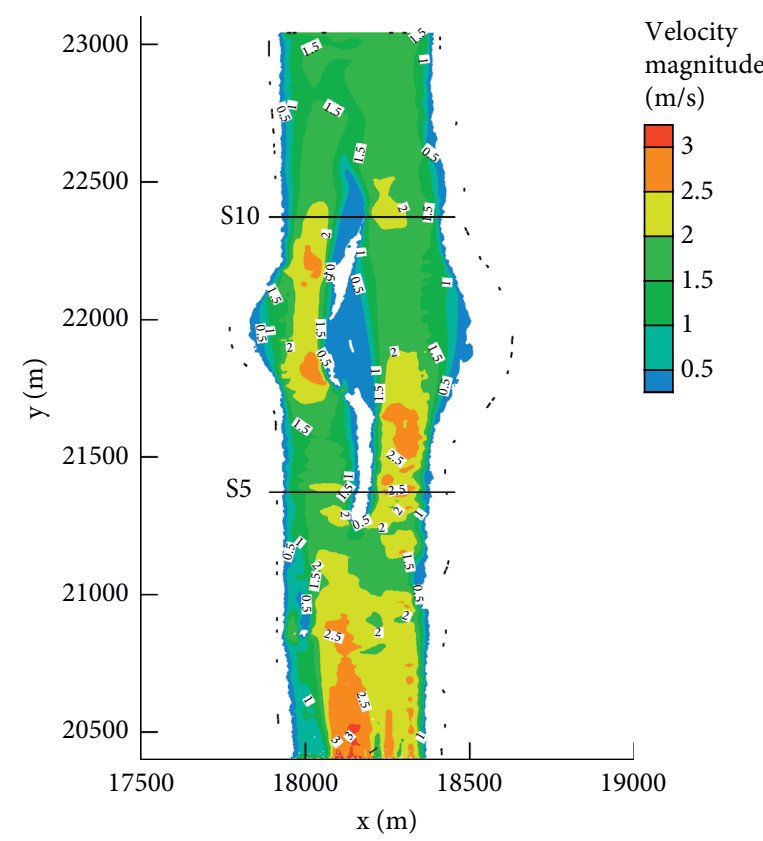

(b)

FIGURE 8: Comparisons of the velocity of flood flow before and after river reconstruction for a 100-year flood. (a) Before reconstruction. (b) After reconstruction.

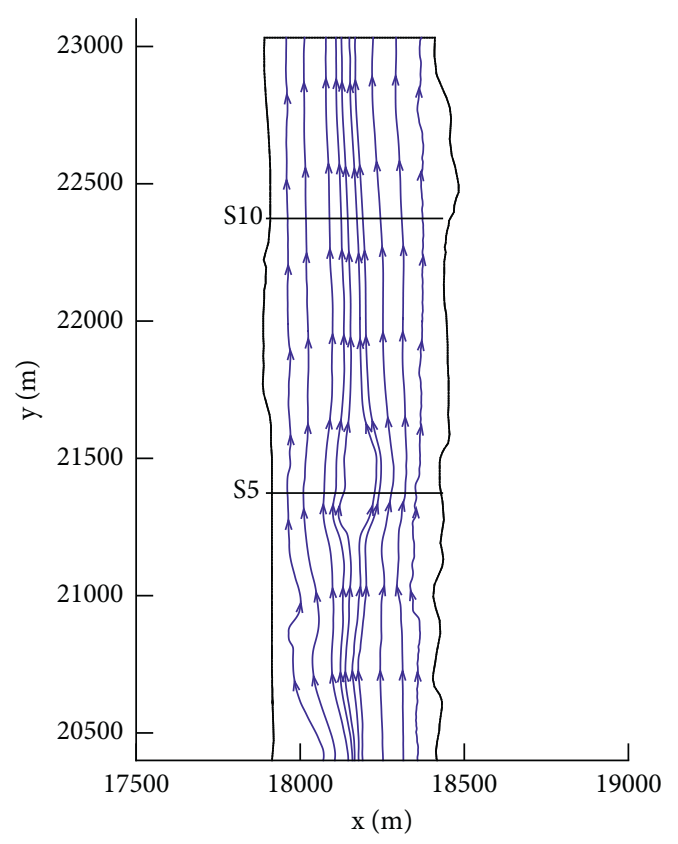

(a)

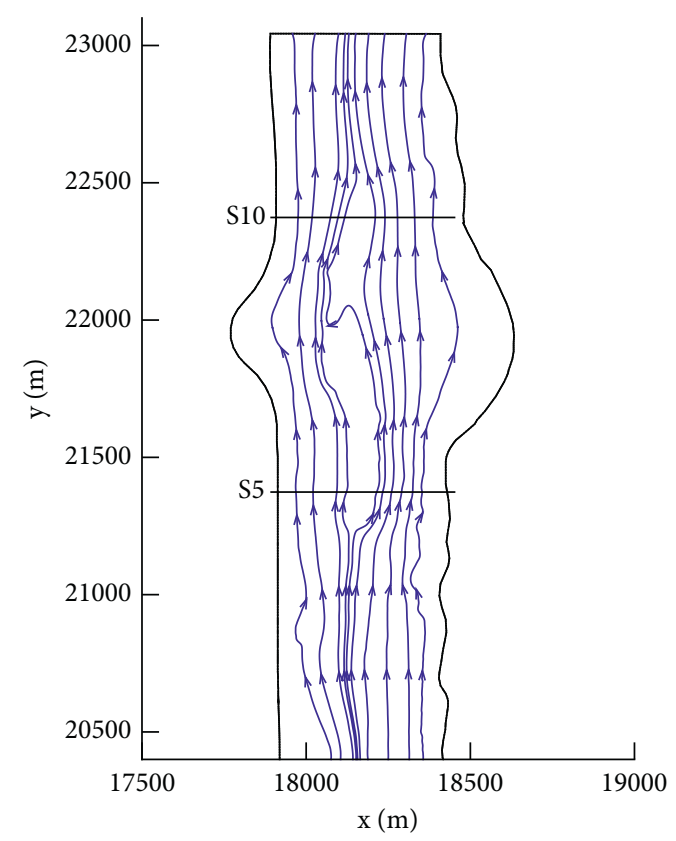

(b)

FIgURe 9: Comparisons of streamlines before and after river reconstruction for a 10-year flood. (a) Before reconstruction. (b) After reconstruction. 


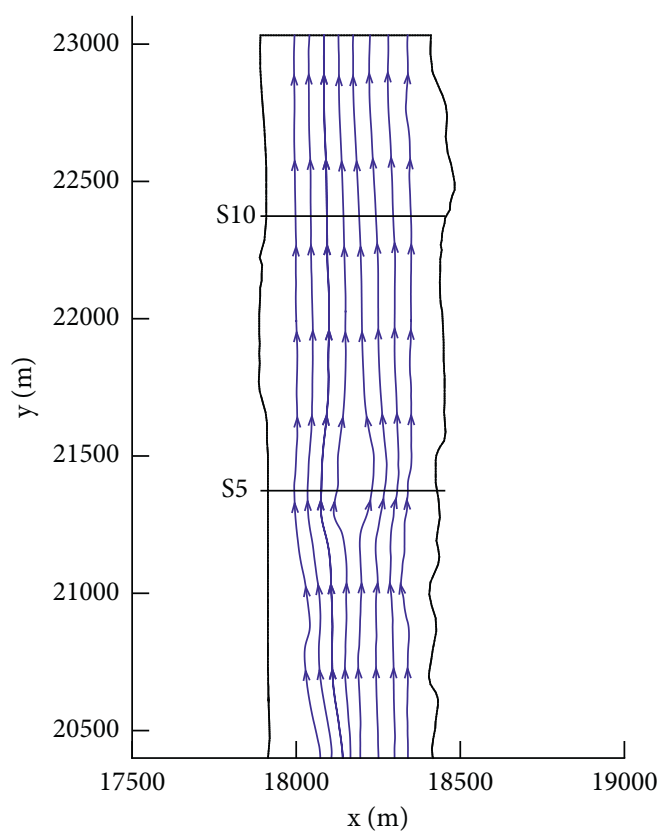

(a)

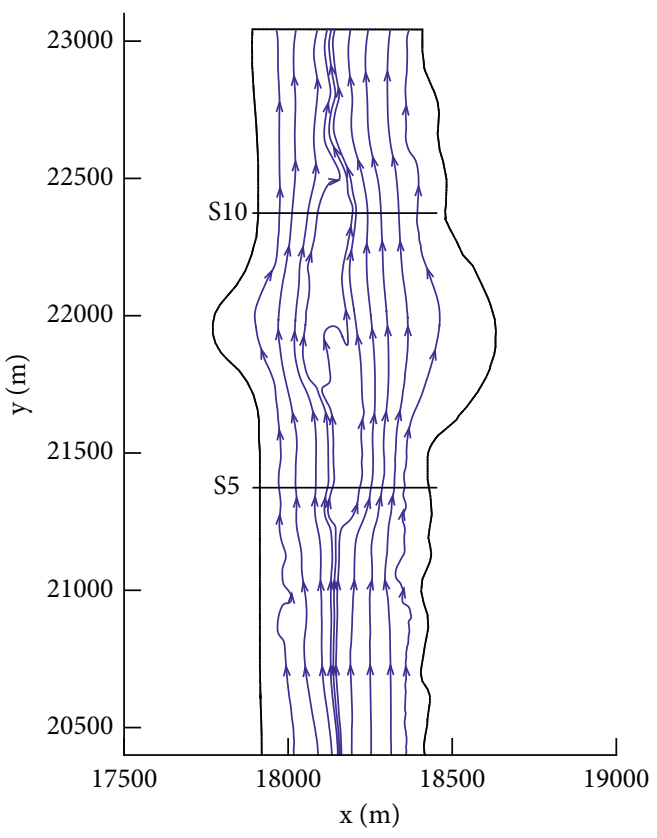

(b)

Figure 10: Comparisons of streamlines before and after river reconstruction for a 100-year flood. (a) Before reconstruction. (b) After reconstruction.

\section{Conclusions}

In order to evaluate the effects of local reconstruction on the flooding of the Ba River in China, a two-dimensional hydrodynamic model was developed, in which the TVD finite volume method was used to solve the $2 \mathrm{D}$ shallow water equations. An unstructured triangular mesh was used to treat the natural boundaries more accurately. Numerical models of the river before and after river reconstruction were developed and the model after river reconstruction was validated by comparing it with results obtained from a $1: 120$ scale physical model. Finally, the effects of local reconstruction on the flooding of Ba River under 10-year and 100-year flood conditions were analyzed by comparing the results before and after local reconstruction. Backwater effects and the flow velocity field were analyzed in depth. The main conclusions are as follows.

By comparing the results of the numerical model with those of the physical model, both the free surface elevation and velocity field were found to be well predicted by the $2 \mathrm{D}$ model developed herein. Due to the small scale of the physical model, the water depth and velocity in the physical model were small and the magnitude of velocity for some of the domains could not be measured accurately. Hence, a 2D numerical model can be a better method for this type of problem.

Backwater effects due to the local reconstruction were obvious for both 10-year and 100-year floods. The backwater length under both flood frequencies reached up to the upstream boundary (Guangyuntan weir) of the computational domain. The maximum water level rises were $0.23 \mathrm{~m}$ at section S5 for a 100-year flood and $0.17 \mathrm{~m}$ at section S5 for a 10-year flood. In addition, the levees for this river channel are safe enough. In general, the effects of local reconstruction on flood water elevation in this river channel were limited.

Comparisons of the velocity of flood flow before and after river reconstruction for the 10-year and 100-year floods showed that the flow field through the reconstructed part (S5 to S10) changed obviously for both flood frequency conditions. For both floods, the maximum velocity between S5 and S10 increased after local reconstruction. Further, after local reconstruction, the streamlines between sections S5 and S10 were changed obviously which means that the flood velocity field became complex, and the maximum magnitude of transverse velocity between S5 and S10 was found to be approximately $0.5 \mathrm{~m} / \mathrm{s}$. The areas of higher and lower velocities for both floods indicated the possibility of local scour or deposition of sediment. Some measures to address this possibility should be considered near these areas.

\section{Data Availability}

All the data used to support the findings of this study are available from the corresponding author upon request.

\section{Conflicts of Interest}

The authors declare that they have no conflicts of interest.

\section{Acknowledgments}

This research was funded by the National Natural Science Foundation of China (Grant no. 51909211); Natural Science Basic Research Plan in Shaanxi Province of China (Grant no. 2019JQ-744); and Natural Science Foundation of Education Department of Shaanxi Province, China (Grant no. 19JK0591). 


\section{References}

[1] M. Beniston, "Trends in joint quantiles of temperature and precipitation in Europe since 1901 and projected for 2100," Geophysical Research Letters, vol. 36, no. 7, 2009.

[2] K. Davor, A. F. Roger, and B. Michaela, "Flood hazard assessment for extreme flood events," Natural Hazards, vol. 84, pp. 1569-1599, 2016.

[3] S. Atabay, K. Haji Amou Assar, M. Hashemi, and M. Dib, "Prediction of the backwater level due to bridge constriction in waterways," Water and Environment Journal, vol. 32, no. 1, pp. 94-103, 2018.

[4] K. J. Kaatz and W. P. James, "Analysis of alternatives for computing backwater at bridges," Journal of Hydraulic Engineering, vol. 123, no. 9, pp. 784-792, 1997.

[5] S. Förster, C. Chatterjee, and A. Bronstert, "Hydrodynamic simulation of the operational management of a proposed flood emergency storage area at the Middle Elbe River," River Research and Applications, vol. 24, no. 7, pp. 900-913, 2008.

[6] D. Tomasz, W. Joanna, and S. Mariusz, "Assessment of the impact of new investments on flood hazard-study case: the bridge on the Warta River near Wronki," Water, vol. 7, pp. 5752-5767, 2015.

[7] G. Petaccia and E. Natale, "ORSADEM: a one dimensional water code for flood inundation modelling," Irrigation and Drainage, vol. 62, pp. 29-40, 2013.

[8] P. Carling, I. Villanueva, J. Herget, N. Wright, P. Borodavko, and H. Morvan, "Unsteady 1D and 2D hydraulic models with ice dam break for Quaternary megaflood, Altai Mountains, southern Siberia," Global and Planetary Change, vol. 70, no. 1-4, pp. 24-34, 2010.

[9] Y. Fan, T. Ao, H. Yu, G. Huang, and X. Li, “A coupled 1D-2D hydrodynamic model for urban flood inundation," Advances in Meteorology, vol. 2017, Article ID 2819308, 12 pages, 2017.

[10] W. Wang, K. Zhou, H. Jing, J. Zuo, P. Li, and Z. Li, "Effects of bridge piers on flood hazards: a case study on the Jialing River in China," Water, vol. 11, no. 6, p. 1181, 2019.

[11] X. Xia, Q. Liang, and X. Ming, "A full-scale fluvial flood modelling framework based on a high-performance integrated hydrodynamic modelling system (HiPIMS)," Advances in Water Resources, vol. 132, Article ID 103392, 2019.

[12] L. Li, M. A. Nearing, M. H. Nichols, V. O. Polyakov, D. Phillip Guertin, and M. L. Cavanaugh, "The effects of DEM interpolation on quantifying soil surface roughness using terrestrial LiDAR," Soil and Tillage Research, vol. 198, Article ID 104520, 2020.

[13] M. Yilmaz and M. Uysal, "Comparison of data reduction algorithms for LiDAR-derived digital terrain model generalisation," Area, vol. 48, no. 4, pp. 521-532, 2016.

[14] R. Wittmann, H.-J. Bungartz, and P. Neumann, "High performance shallow water kernels for parallel overland flow simulations based on FullSWOF2D," Computers \& Mathematics with Applications, vol. 74, no. 1, pp. 110-125, 2017.

[15] R. Vacondio, A. Dal Palù, A. Ferrari, P. Mignosa, F. Aureli, and S. Dazzi, "A non-uniform efficient grid type for GPUparallel Shallow Water Equations models," Environmental Modelling \& Software, vol. 88, pp. 119-137, 2017.

[16] J. Hou, Y. Kang, C. Hu, Y. Tong, B. Pan, and J. Xia, “A GPU-based numerical model coupling hydrodynamical and morphological processes," International Journal of Sediment Research, vol. 35, no. 4, pp. 386-394, 2020.

[17] J. Ahn, Y. Na, and S. W. Park, "Development of two-dimensional inundation modelling process using MIKE21 model," KSCE Journal of Civil Engineering, vol. 23, no. 9, pp. 3968-3977, 2019.
[18] MIKE 21, Flow Model FM Hydrodynamic and Transport Module: Scientific Documentation, 2012. 